\title{
Comparison of primary headaches characteristics in the community and in a tertiary care clinic
}

\section{Comparação das características das cefaleias primárias na comunidade com as de um centro terciário de atendimento}

Ariovaldo Alberto Silva Jr

Tese de Doutorado, Instituto de Ciências Biológicas da Universidade Federal de Minas Gerais (ICB-UFMG) (2011), Belo Horizonte MG, Brazil. Orientador: Antônio Lúcio Teixeira

Correspondence: Ariovaldo Alberto Silva Jr; Rua dos Timbiras 1.940/ sala 803/ Lourdes; 30140-061 Belo Horizonte MG - Brasil; E-mail:ariovaldo.junior@unifenas.br

\begin{abstract}
Background: Epidemiological studies focusing on primary headaches are often difficult to compare, since they are sometimes conducted in the community and sometimes in the specialty care. Since target populations are different, comparing results may contribute to a better understanding on the headaches and on barriers to care. Objectives: To contrast the epidemiological characteristics of headache sufferers identified from the population and from specialty care. Methods: Family Health Program (FHP) agents interviewed all inhabitants from Capela Nova (MG). Those screened as having chronic daily headaches (CDH) were invited to participate in neurological, dental, and physiotherapy assessments. Additionally, those living in one of the city's micro-regions (chosen at random) were enrolled to participate in neurological assessment regardless of the headache frequency. Finally, the same multidisciplinary team involved in the community research assessed all patients seen at the outpatient headache clinic of Universidade Federal de Minas Gerais (AMBCEF-UFMG) over a 4 months period. Headaches were diagnosed according to the second edition of the International Classification of Headache Disorders (ICHD-2), and temporo-mandibular disorders (TMD) were classified as per the Research Diagnostic Criteria (RDC). Results: Of 1,605 inhabitants from the population, 1,050 (65.4\%) had headaches and 57 (3.6\%) had CDH. The micro-region sample consisted of 258 inhabitants. Migraine happened in $18.2 \%$ of them, and tension-type headache (TTH) in $22.9 \%$. Frequency of these headaches among 76 headache sufferers in the sample was respectfully 61.8 and $77.6 \%$. Finally, among headache sufferers in the outpatient clinic, $78.8 \%$ had migraine and $20.4 \%$ had TTH. In the population, prevalence of TMD in those with CDH was $58.1 \%$, while in the clinic it was $80 \%$. Women were more likely to suffer from headaches in all samples, but the proportion of men was higher in the community and lower in the population ( $p<0.05)$. Conclusions: Population prevalence and demographic characteristics found in our study are aligned with what has been described. Relative frequency of migraine and TTH vary substantially in the community relative to the population, but the same was not true for CDH and TMD, suggesting that they may be more determined by neurobiological factors than by the environment. Further comparative studies are necessary in order to understand not only determinants of disease, but barriers to seeking medical care.
\end{abstract}

Key words: epidemiology, primary headaches, chronic daily headaches, tension-type headaches, migraine. 